\title{
Exit Exams for College Flight Programs: Redundant Activity or Certification of Competency?
}

\author{
Richard O. Fanjoy, John P. Young, Brian G. Dillman
}

Purdue University

\begin{abstract}
A wide variety of training organizations prepare prospective pilots for Federal Aviation Administration (FAA) certification. Students enrolled in collegiate flight training programs also complete several FAA certifications; however, their graduation is contingent upon completion of an academic curriculum rather than standardized exit examinations that measure competency for professional flight duties within the aviation industry. Since establishment in 1988, the Council on Aviation Accreditation (CAA) has provided a measurement of collegiate flight program quality and attempted to promote curricular standardization; however, the number of college flight programs currently accredited remains relatively small. This paper presents the results of a survey that addressed issues related to the establishment of a standardized college flight program exit examination. Many flight program administrators currently believe that existing FAA certifications provide a solid foundation for program graduates and that grooming to meet professional industry standards is the responsibility of the hiring airline/operator. Survey findings suggest an interest in the establishment of four-year flight program exit examinations, but respondents expressed a concern about the form of such exams and how to address those who fail. The findings described in this paper were analyzed to evaluate support in the aviation education community for standardized exit examinations as well as to promote a dialogue between aviation industry and flight program administrators on the utility of exit examinations.
\end{abstract}

\section{INTRODUCTION}

Professional pilot competency is an aspect of the aviation industry that is frequently taken for granted by the traveling public. However, an accident or incident that results from pilot error or the appearance of aircrew incompetence quickly results in significant media coverage of air carrier operations and frequently leads to substantial loss of revenues. Initial and recurring Federal Aviation Administration (FAA) flight examinations are designed to certify aviation competence of new and experienced pilots. A lengthy track record of aircraft mishaps attributed to pilot error, however, brings into question the accuracy of FAA evaluations as the sole measurement of professional competency. Many professional pilots are graduates of two- and fouryear college flight programs that require a number of FAA flight certifications as well as traditional college coursework. The resources and curriculum associated with college programs vary widely and requirements for program completion vary accordingly. The lack of standardized program expectations and ongoing concern over pilot competency in a more complex and technologically advanced flight environment has prompted interest in some form of exit examination to certify a minimum level of competency for professional flight employment.

Various forms of exit examination are designed to certify competency in a desired area of knowledge and commonly used in secondary education as well as for admission to post-secondary academic programs. Exit examinations are a common part of the board certification process for many professions. The FAA has established Practical Test Standards, which define the criteria for final certification or exit examination for all certificates and ratings issued under Federal Aviation Regulations (FARs). Certifying a certain level of competency is the end goal of pilot examiners and FAA Practical Test Standards provide guidelines by which applicants are to be judged by examiners. Under current regulations, individuals who fail part of a flight certification test are required to receive remedial training on the area or areas that were found to be deficient and must then present an endorsement from a qualified instructor before 
a certification retest may be attempted. There is currently no limit to the number of times an applicant may attempt to perform an unsatisfactory maneuver during rechecks. As a result, a relatively weak applicant may eventually be successful in completing the maneuver and obtaining the desired certificate or rating. This marginal applicant receives the same certification documents as an applicant who was successful on the first attempt.

On January 27, 2005, the National Transportation Safety Board recommended that the Federal Aviation Administration "require all Part 121 and 135 air carriers to obtain any notices of disapproval for flight checks for certificates and ratings for all pilot applicants and evaluate this information before making a hiring decision, and conduct a study to determine whether the number of flight checks a pilot can fail should be limited and whether the existing system of providing additional training after a notice of disapproval is adequate for pilots who have failed multiple flight checks" (NTSB, 2005, p. 3). This recommendation was in response to a recent air carrier accident that was a result, in part, from poor training and multiple retests by the pilot involved. In this particular case, the accident pilot had received nine rechecks during the course of professional certification (NTSB, 2005). Although many Part 121 and 135 operators question an applicant's pass/fail rates during the job application process, potential employers are currently not privy to the number of times a specific flight certification test was failed. While making this information available to commercial operators may seem like a legitimate step, such legislation may lead flight training providers to "teach the test" rather than trying to provide a broad and well-rounded introduction to the aviation environment. Wright (2002), an FAA flight standards manager, views pilot certification, type ratings, and flight instructor/pilot examiner qualifications as "oriented towards passing the knowledge and practical tests rather than outlining a scenario-based training and testing approach" (p. 13).

The majority of flight training is completed under the requirements of FAR Parts 61 and 141. After flight training, an applicant must successfully complete a certification exam to demonstrate proficiency in the required areas for the desired pilot certificate or rating. The methods by which examiners are qualified and exams are administered under Parts 61 and 141 are different. For Part 61 and 141 schools without examining authority, Designated Pilot Examiners (DPE) are selected through a National Examiner Board process that screens DPE applicants and serves as a clearinghouse for local Flight Standard District Offices (FSDO) when a need appears in a specific geographic location. All DPEs are selected directly by the FSDO that has jurisdiction over a geographic area where the DPE will provide services. Part 141 schools with examining authority, on the other hand, have a Chief Instructor approved by the FSDO, similar to the way DPEs are certified. Chief Instructors, however, have the authority to designate Check Instructors who pass certain proficiency tests and are then approved by the FSDO. Differences in the way these examiners are selected and certified, may lead to unequal scrutiny of applicants during certification exams.

Another difference between Part 61 and 141 schools is the way certification exams are administered. According to FAR 61.43 (FAA, 2005a), all applicants must demonstrate satisfactory proficiency and competency within the approved standards. This regulation further states that if an applicant fails any area of operation, that applicant fails the practical test. Reference to FAR 141.67 (FAA, 2005b) reveals that tests given by a flight school which holds examining authority must be approved by the FAA and be equal in scope, depth, and difficulty to requirements established in Part 61. On the surface, it would appear that there is little difference between the requirements of these sections; however, examiners at Part 141 schools with examining authority have the ability to discontinue a certification exam if an applicant fails to perform satisfactorily in a given area without issuing a Notice of Disapproval or "Pink Slip." On the other hand, Designated Pilot Examiners are required to issue a Notice of Disapproval for any unsatisfactory area. An Aircraft Owners and Pilots Association staff member (AOPA, personal communication, April 5, 2005) notes that Part 141 school examiners 
may stop an evaluation at any time, allow the student to be given remedial training, and then retest. In this instance, no documentation is completed or sent to the FAA until all testing is completed. It is not the purpose of this paper to make a determination of which system produces better pilots (Part 61 or 141 training), but to highlight standardization issues for discussion.

In an effort to formally accredit and promote the quality of college and university aviation programs, the Council on Aviation Accreditation (CAA) was established in 1988 (CAA, 2005a). The goals of CAA accreditation are to "stimulate collegiate aviation program excellence and self improvement; establish uniform minimum educational quality standards; and increase the credibility, integrity, and acceptance of collegiate aviation programs within institutions of higher education and aviation communities" (CAA, 2005b). Certain aviation program content areas must be covered to meet CAA standards. Various aspects of a college program are evaluated through self-assessments by the host school and through external assessments by a CAA review team. Flight education is one such aviation program that can be accredited. A recent CAA initiative is to shift criteria for future accreditation from content-based assessment to outcomes-based assessment. While CAA has provided a viable avenue for aviation program standardization, to date only 16 of 87 potential associate and bachelors aviation flight education degree programs have been accredited and some have declined participation in the current CAA accreditation process (CAA, 2005c; University Aviation Association, 2003).

Professional and educational competency exams are not new. In the medical field, new doctors must pass medical board exams; new lawyers must pass the bar exam; accountants must pass CPA (Certified Public Accountant) exams, and the list goes on. In aviation, the National Business Aircraft Association offers a comprehensive exam to certify corporate aviation managers. Likewise, the American Association of Airport Executives provides certification at two levels: the Certified Manager and Accredited Airport Executive. In graduate education, doctoral degree candidates must pass their preliminary exams (summary oral and/or written questions regarding their course subject areas) and similarly, many masters degree candidates must defend their theses or directed projects.

A recent initiative established to ensure the preparedness of pilots to enter this career field is the Professional Aviation Board of Certification (PABC). This independent, nonprofit organization strives to enhance aviation and public safety through its education, assessment, and research activities (Wolfe, 2005). Stakeholders in this endeavor include educators, employers, government agencies, aircraft manufacturers and support services, pilots, and the public. PABC 's focus is to provide a clear and comprehensive description of industry-defined expectations for entry-level professional pilots, thereby enabling both pilots and educators to reduce the cost of effective career preparation. In addition to this initiative, PABC plans to develop and ultimately administer an examination to address employer expectations. The test will provide a rigorous and scientifically validated assessment of the knowledge, skills, and capabilities that today's flight crew needs to be successful during an employer's initial training program. The PABC certification examination will differ from that of the FAA by both addressing a wider array of subject matter and assessing the depth of a pilot's capability to apply his/her knowledge in addressing a variety of practical scenarios. Passing such a test will provide both the pilot and the employer with an invaluable credential. Successful completion will provide a clear indication of a pilot's motivation and capabilities in subject areas that employers have signified are important. Employers may then expect the certified pilot to be academically ready to enter initial training, thereby reducing the time and cost of that training program.

The focus of collegiate aviation programs is to produce a safe and proficient professional pilot who has completed the requirements for a college degree. However, attained knowledge and skills can degrade over the course of a four-year degree program. Accordingly, it seems prudent to assess mastery of requisite subject areas at program completion. This is especially true in aviation, where newly minted professional pilots may not only endanger 
themselves, but, in commercial service, could also cause harm to others. This likelihood does not apply to most academic majors.

While the exit exam may present an inviting prospect for aviation program enhancement, there are concerns with its implementation. Aviation program curricula could be restructured in response to exit exam competency expectations, but such change will be no less difficult to address than acceptance of accreditation standards currently being considered by institutions with limited resources and/or specialized program requirements. Most aviation curricula already contain a large percentage of technical courses that are carefully tied to current resources and that allow little flexibility for significant change. Another issue is how to develop and maintain confidential, standardized exit examinations that meet the needs of the aviation industry. Different air carriers, for example, have different expectations for prospective employees and may not want to share their special needs with competitors. Finally, it is unclear what process might be used to address students identified on exit exams as weak or unacceptable. How many times and how frequently could they retake a written exit exam? How would practical flying skills be evaluated? Currently, weak college students may obtain minimum passing grades and still graduate with their peers. Unlike military or aviation industry personnel, a weak or unstable student in higher education cannot be summarily dropped from the program without due process and/or retraining opportunities. A poorly performing collegiate aviation student may be identified for a period of probationary continuation and reevaluation, however such students are not normally dismissed until a significant pattern of poor performance or misconduct has been established at the college/university. Also, classroom grades do not always correlate with practical pilot skills. If exit exams are to be used, educators must carefully consider all the implications of application and possible failure. Flight program administrators, regulatory agencies, and the aviation industry all have a vested interest in this issue.

\section{METHODOLOGY}

A phone survey (Fanjoy \& Wirth, 2003) was developed to assess methods of measuring professional pilot competency upon completion of collegiate flight programs. The survey was designed to identify forms of professional pilot exit examination currently in use, answer the question of whether support was present for the development of a standardized exit examination, assess what form such an examination might take, and determine what actions would be appropriate if a prospective graduate did not successfully complete the examination. The survey was administered to key faculty members or administrators of four-year aviation degree programs to include the department chair, aviation program director, or chief flight instructor. To keep the sample size reasonable, only those schools listed in the University Aviation Association's Collegiate Aviation Guide (2003) with flight training-related degree programs were surveyed. The sample was further restricted to programs with fouryear baccalaureate flight degrees, since such programs presumably provide more comprehensive preparation for professional flight employment. An attempt was made to collect information from each of the 42 schools listed in the Collegiate Aviation Guide that offer four-year aviation flight degrees. The authors were able to obtain survey information from 29 of 42 schools for a response rate of $63 \%$.

\section{FINDINGS}

Respondents were advised of the purpose of the current study, received assurances of confidentiality, and then given the survey questions. The first question asked whether the school's aviation department used a comprehensive measurement to assess overall competency of flight students who were approaching graduation and if so, what methods were used. Some respondents were initially unsure what constituted a comprehensive measurement. The researchers told them that this question addressed any form of exit exam that measured student preparation 
for a professional flight career. All of the respondents stated that their program did not currently administer a formal exit exam. However, seven respondents stated their program uses a capstone course during the senior year of education that they believed served the same purpose as an exit exam. Four respondents stated that their program required completion of the Certified Flight Instructor (CFI) certificate, and were confident that the CFI served as an accurate measure of professional pilot competency. Respondents from nine schools were emphatic that the series of FAA evaluations (private and commercial pilot certification, instrument rating, etc.) built into their four- year programs provided an approved validation of aviation competency. The remaining nine respondents had no further comment to this question.

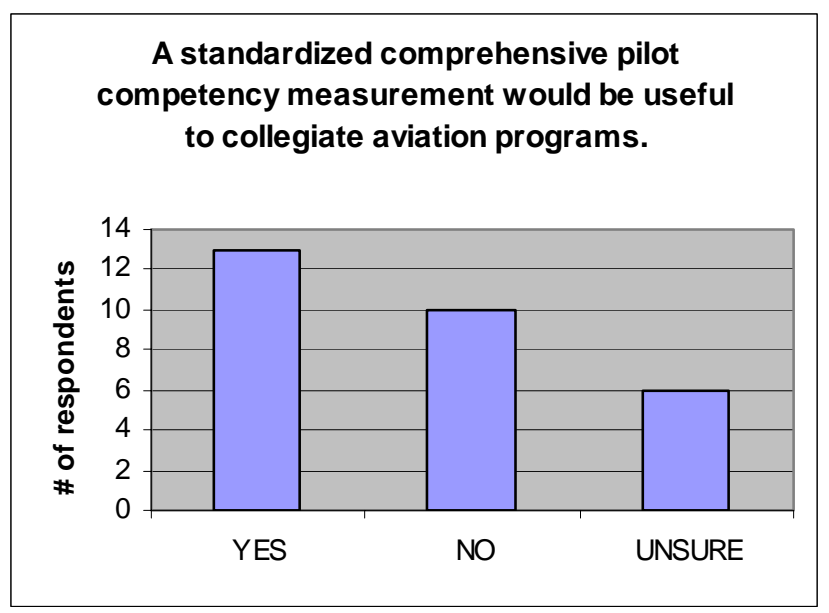

Figure 1. Standard measurement utility

The second question addressed the utility of a standardized, comprehensive pilot competency measurement for collegiate aviation programs and what form such a measurement might take (see Figure 1). Although thirteen respondents thought a standardized, comprehensive measurement was a good idea, ten did not, and six were unsure. Several respondents who were opposed to the idea were concerned with the measurement format and whether it would accurately address the variety of resources and curricula among diverse flight programs. Their stance was that standardization beyond anything required by current FAA evaluation standards might have a negative impact on the strengths of their current program format. Those who supported the measurement suggested a variety of possible formats to include: combined oral/practical/written (9), oral/practical (5), standardized capstone course (3), ATP written and simulator evaluation (1), mandated CFI completion (1), and some method of tracking progress after graduation (1) (see Figure 2).

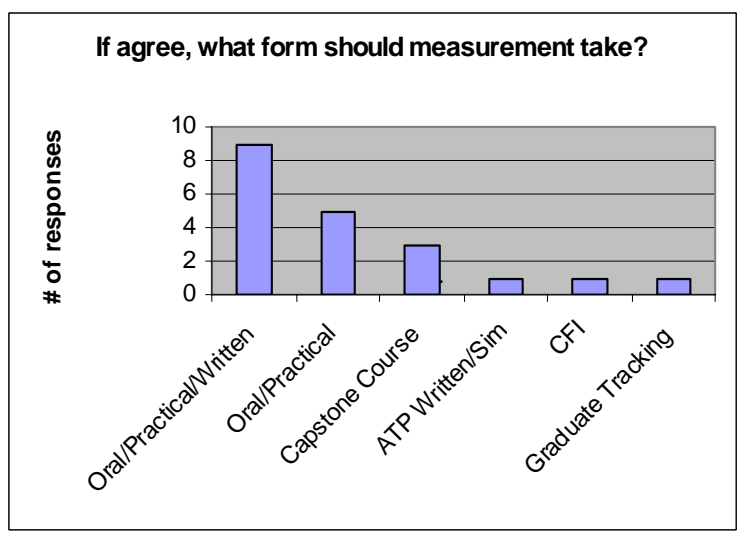

Figure 2. Exit exam measurement methods

The third question addressed how to handle students who did not meet a prescribed measurement standard (see Figure 3). Would they be allowed to graduate? Was additional training required? How should the progress of such students be addressed in a collegiate environment? Several respondents (10) indicated support for additional training and retest to address comprehensive measurement failures. Eight of those surveyed said that recognition with a special certificate should be provided for successful measurement rather than penalize those who do not meet a standardized result. Four said that progress of those who fail should be monitored for potential program elimination; however, these respondents also noted that flight faculty may be unable or unwilling to eliminate flight students who are participating in an academic curriculum. Three respondents said that if the student has passed required FAA certifications and met the college academic requirement for graduation, any further certification of professional competency should be the responsibility of the future employer. One suggested option was to allow students who did not meet the standard to switch majors. This option has been used with some success at several institutions, but may have a negative 
impact on the gaining department or cause the flight program to be seen as elitist. The last question asked if the respondent would support an effort to develop a standardized measurement to assess CAA-accredited, four-year degree flight programs. Ten respondents said yes, eleven said no, and three said they needed more information. Three said they would support this initiative if it affected the program and not individual students. Two said they could only support such a measurement if it was met with industry-wide support.

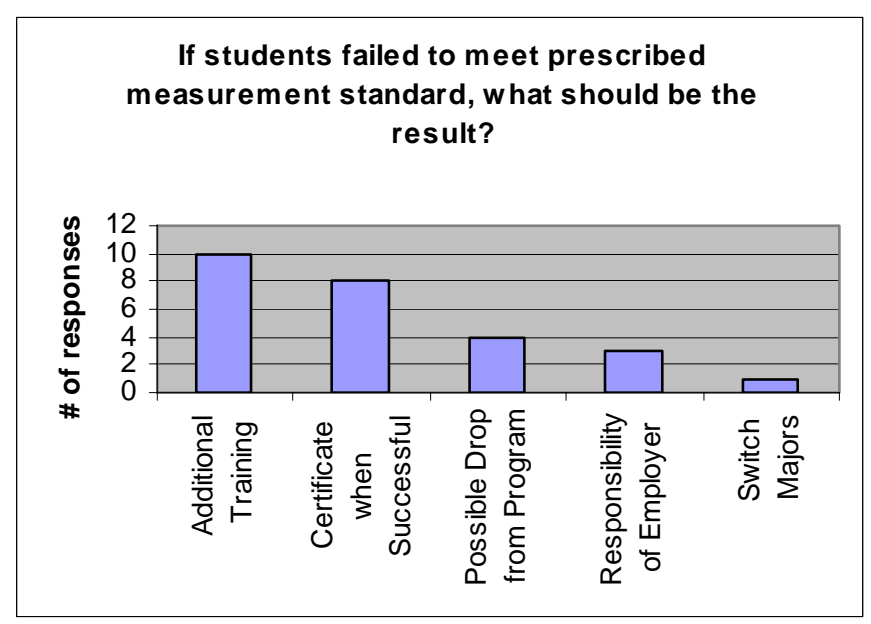

Figure 3. Exit exam failure options

\section{DISCUSSION}

The survey conducted during the present research reflects some college flight program administrator support for a standardized professional pilot educational exit exam. However, survey respondents expressed great concern with the design and implementation of such a test. The need for an exit exam measurement seems appropriate given the current level of responsibility and degree of expertise associated with operation of airline and corporate aircraft in passenger service. Historically, the "gold standard" for professional pilot employment has been appropriate FAA certification and significant flight time experience. When a prospective pilot employee has met these criteria, it has become the responsibility of the employer to add final polish with training in appropriate equipment and company operations/procedures. Due to the technical complexity of modern aircraft and changing nature of the operational flight environment, however, expectations have never been greater for competency of college flight program graduates. Financial drain related to costly resources and market competition may have led many operators to assign a lower priority to training. The expectations of both collegiate flight program administrators and the aviation industry seem to be that the other will take necessary steps to make up training shortfalls.

The FAA is not chartered to determine a professional level of competence. Instead, FAA certifications measure an ability to safely operate aircraft within the minimum level of competency described by the certification standards. Prospective employers supplement this "threshold level" of certification with other criteria, such as total flight time and educational degrees. Although several survey respondents for the present study felt that FAA certifications appropriately addressed their program needs, this position may reflect resource limitations or limited interaction with prospective employers.

It seems appropriate that collegiate flight program administrators revisit the expected competency of their program graduates. Should they be able, for example, to assume duties in a modern turbine aircraft with minimal training? Should such a measurement of competency be based on program resource constraints or on an industry standard? Is a common industry standard possible for college flight program graduates? Graduates of bridge programs, as well as those from programs with advanced aircraft and simulator training resources seem more likely to be hired by regional carriers, yet the question remains as to their preparation. Should there be an established standard that will lead to acceptance of aviation competency by all employers? Such questions must be resolved through open discussion between college program educators and industry representatives.

If a standardized exit exam can be developed, two other issues must be addressed. The first is an appropriate response to exit exam failures in a college academic environment. Most students have a significant financial investment in such programs. Is it 
ethical after four years of investment to deny a college degree to students who complete all curricular requirements but fail an exit exam? Should retakes be allowed? If so, how many and how often? Guidelines used by other professional certifying organizations may be instructive in this area. Some survey respondents suggest a special certificate should be issued for successful completion of a standardized exit exam, rather than penalties for those who fail. Such certification should not be tied to degree-program completion but should receive favorable consideration by all aviation employers. Others suggest that retraining be provided until such a time that special certification can be awarded. The issue of exit exam measurement in a college context is not an easy one to resolve. A second issue is how to address the development and security of such examinations? Should this activity fall under the purview of a certification agency such as the University Aviation Association, Council on Aviation Accreditation, or Professional Aviation Board of Certification? What curricular impact might be expected for participating programs? Should participation in a standardized exit exam program be mandatory to insure employment? Should there be a practical component to exit examinations? How would that type of evaluation be addressed across the wide spectrum of equipment resources present at flight training institutions? For an exit exam standard to be accepted, it will require industry support and acceptance by a broad base of flight program administrators.

Many college flight programs have taken steps to address the issue of desired professional pilot competency. Some survey respondents indicated they have a capstone course during the senior year that addresses industry specific issues in a classroom context. It is unclear how such courses provide a measurement of individual expertise, but certainly important information is provided to students. Some schools require flight instructor certification with the expectation that during such training, students will acquire experience and knowledge above and beyond that required for simple aircraft operation. One respondent cited a local program requirement for seniors to successfully complete the Air Transport Pilot written examination. This method seems to address the highest level of FAA knowledge- based competency testing, but may not offset a practical equivalent or advanced equipment competency. Many respondents stated that they just did not have the resources to provide more than the basic, FAA-certified, commercial pilot level of competency. All respondents seemed to embrace the ethical responsibility to prepare program graduates for commercial employment, but felt helpless to do so with resource constraints and the wide variety of industry expectations.

\section{CONCLUSIONS}

Exit examinations that assess professional pilot competency are an important issue for both college program administrators and airline/corporate operators. College program administrators want to produce a competent graduate with a well-rounded education who will be highly prized by prospective employers. Prospective employers want to hire top-quality, professional pilots who inspire confidence in the traveling public and easily adapt to the operation of company equipment and procedures. Both entities must deal with resource limitations and current pressure on aviation industry operations. Many college aviation programs have depended upon FAA certification as a measure of graduate competency, which may not be sufficient to establish a professional level of performance. In light of these factors, it seems crucial that a dialogue be initiated between aviation industry officials and flight program administrators to determine the practicality and importance of a professional pilot competency standard and how such a standard might be implemented. Further research into competency examinations used in other professional fields may provide additional insight to this important issue. 


\section{REFERENCES}

Council on Aviation Accreditation (CAA, 2005a). CAA short history. Retrieved April 6, 2005, from http://www.caaaccreditation.org/historys.html

Council on Aviation Accreditation (CAA, 2005b). CAA goals. Retrieved April 6, 2005, from http://www.caaaccreditation.org/goals.html

Council on Aviation Accreditation (CAA, 2005c). CAA member institution accreditation status. Retrieved April 6, 2005, from http://www.caaaccreditation.org/ $117 \% 20 \mathrm{mem} \% 20$ inst\%20accred\%20status.pdf

Fanjoy, R. O. \& Wirth, R. C. (2003). [Survey of collegiate educators in 4-year aviation schools offering flight majors]. Unpublished raw data.

Federal Aviation Administration (FAA, 2005a). 14 C.F.R $\S 61.43$

Retrieved April 15, 2005, from http://ecfr.gpoaccess.gov/cgi/t/text/text$\mathrm{idx} ? \mathrm{c}=\mathrm{ecfr} \& \mathrm{sid}=6862013 \mathrm{eed} 1 \mathrm{e} 3 \mathrm{a} 7675 \mathrm{e} 4 \mathrm{ed} 1369 \mathrm{~b} 9 \mathrm{~b} 938 \& \mathrm{rgn}=\mathrm{div} 8 \& \mathrm{view}=$ text\&node $=14: 2.0 .1 .1$. 2.1.1.26\&idno $=14$

Federal Aviation Administration (FAA, 2005b). 14 C.F.R $§ 141.67$

Retrieved April 15, 2005, from http://ecfr.gpoaccess.gov/cgi/t/text/text$\mathrm{idx} ? \mathrm{c}=\mathrm{ecfr} \& \mathrm{sid}=6862013 \mathrm{eed} 1 \mathrm{e} 3 \mathrm{a} 7675 \mathrm{e} 4 \mathrm{ed} 1369 \mathrm{~b} 9 \mathrm{~b} 938 \& \mathrm{rgn}=\mathrm{div} 8 \& \mathrm{view}=$ text $\&$ node $=14: 3.0 .1 .1$. 2.4.1.4\&idno $=14$

National Transportation Safety Board (NTSB, 2005). Safety Recommendation A-05-01 \& A-05-02. Retrieved March 23, 2005, from http://www.ntsb.gov/recs/letters/2005/A05_01_02.pdf

University Aviation Association (2003). Collegiate Aviation Guide. Auburn, AL: Author.

Wolfe, P.J. (2005). Introduction to the PABC concept of professional pilot development. Unpublished manuscript.

Wright, R. A. (2002). White paper: Changes in general aviation flight operations and their impact on system safety and flight training. Retrieved March 24, 2005, from http://www.faa.gov/avr/ afs/fits/program/whitepaper.doc 